\title{
Observation of efficient population of the red-emitting state from the green state by non-multiphonon relaxation in the $\mathrm{Er}^{3+}-\mathrm{Yb}^{3+}$ system
}

\author{
Jiahua Zhang, Zhendong Hao, Jing Li, Xia Zhang, Yongshi Luo and Guohui Pan
}

The rare earth $\mathrm{Er}^{3+}$ and $\mathrm{Yb}^{3+}$ codoped system is the most attractive for showcasing energy transfer upconversion. This system can generate green and red emissions from $\mathrm{Er}^{3+}$ under infrared excitation of the sensitizer $\mathrm{Yb}^{3+}$. It is well known that the red-emitting state can be populated from the upper green-emitting state. The contribution of multiphonon relaxation to this population is generally considered important at low excitation densities. Here, we demonstrate for the first time the importance of a previously proposed but neglected mechanism described as a cross relaxation energy transfer from $\mathrm{Er}^{3+}$ to $\mathrm{Yb}^{3+}$, followed by an energy back transfer within the same $\mathrm{Er}^{3+}-\mathrm{Yb}^{3+}$ pair. A luminescence spectroscopy study of cubic $\mathrm{Y}_{2} \mathrm{O}_{3}: \mathrm{Er}^{3+}, \mathrm{Yb}^{3+}$ indicates that this mechanism can be more efficient than multiphonon relaxation, and it can even make a major contribution to the red upconversion. The study also revealed that the energy transfers involved in this mechanism take place only in the nearest $\mathrm{Er}^{3+}-\mathrm{Yb}^{3+}$ pairs, and thus, it is fast and efficient at low excitation densities. Our results enable a better understanding of upconversion processes and properties in the $\mathrm{Er}^{3+}-\mathrm{Yb}^{3+}$ system. Light: Science \& Applications (2015) 4, e239; doi:10.1038/lsa.2015.12; published online 16 January 2015

Keywords: energy transfer; erbium-ytterbium system; upconversion luminescence

\section{INTRODUCTION}

Infrared to visible upconversion luminescence has been extensively studied for its fundamental value $\mathrm{e}^{1-3}$ and its various potential applications in upconversion lasers, ${ }^{4}$ bioimaging, ${ }^{5}$ etc. The codoping of $\mathrm{Er}^{3+}$ and a high concentration of sensitizer $\mathrm{Yb}^{3+}$ forms the most attractive energy transfer upconversion (ETU) system. Under infrared (980 nm) excitation of the sensitizer $\mathrm{Yb}^{3+}$, this system can generate green and red upconversions originating from the ${ }^{4} \mathrm{~S}_{3 / 2} \rightarrow{ }^{4} \mathrm{I}_{15 / 2}$ and ${ }^{4} \mathrm{~F}_{9 / 2} \rightarrow{ }^{4} \mathrm{I}_{15 / 2}$ transitions of $\mathrm{Er}^{3+}$, respectively. Unlike the green upconversion, the red upconversion benefits from several possible excitation mechanisms. ${ }^{6,7}$ Multiphonon relaxation (MPR) from the upper ${ }^{4} S_{3 / 2}$ state and ETU from the lower intermediate ${ }^{4} \mathrm{I}_{13 / 2}$ state are generally considered dominant at low infrared excitation densities because other mechanisms involving three photon processes ${ }^{6,7}$ become important only at high infrared excitation densities, ${ }^{8}$ which is not the topic of this work.

The MPR is not the only mechanism for populating the ${ }^{4} \mathrm{~F}_{9 / 2}$ from the ${ }^{4} S_{3 / 2}$; a non-MPR mechanism was proposed earlier, ${ }^{8}$ but it has not been considered important since then. This mechanism involves two sequential energy transfers between $\mathrm{Er}^{3+}$ and $\mathrm{Yb}^{3+}$. The first step is a well-known cross-relaxation (CR) energy transfer from $\mathrm{Er}^{3+}$ in the ${ }^{4} \mathrm{~S}_{3 / 2}$ excited state $\left({ }^{4} \mathrm{~S}_{3 / 2} \rightarrow{ }^{4} \mathrm{I}_{13 / 2}\right)$ to $\mathrm{Yb}^{3+}$ in the ground state $\left({ }^{2} \mathrm{~F}_{5 / 2} \leftarrow{ }^{2} \mathrm{~F}_{7 / 2}\right),{ }^{9}$ resulting in the excitation of $\mathrm{Er}^{3+}{ }^{4} \mathrm{I}_{13 / 2}$ and $\mathrm{Yb}^{3+}$ ${ }^{2} \mathrm{~F}_{5 / 2}$. The subsequent step is an energy back transfer from the $\mathrm{Yb}^{3+}$ $\left({ }^{2} \mathrm{~F}_{5 / 2} \rightarrow{ }^{2} \mathrm{~F}_{7 / 2}\right)$ excited by the $\mathrm{CR}$ to $\mathrm{Er}^{3+}$ in the ${ }^{4} \mathrm{I}_{13 / 2}$ state $\left({ }^{4} \mathrm{~F}_{9 / 2} \leftarrow{ }^{4} \mathrm{I}_{13 / 2}\right)$ to promote the excitation of $\mathrm{Er}^{3+}{ }^{4} \mathrm{~F}_{9 / 2}$. Hence, the $\mathrm{CR}$ can be divided into two parts: one is followed by the energy back transfer, CRB, and the other is not followed by the energy back transfer, CRNB. The $\mathrm{Yb}^{3+}$ induced green emission quenching of $\mathrm{Er}^{3+}$ by the $\mathrm{CR}$ has been widely recognized. ${ }^{9,10}$ However, the population of the ${ }^{4} \mathrm{~F}_{9 / 2}$ by the CRB from the ${ }^{4} S_{3 / 2}$ has rarely been studied or valued in both photoluminescence (PL) and upconversion luminescence (UCL).

In this article, we report an observation of the CRB in cubic $\mathrm{Y}_{2} \mathrm{O}_{3}$ : $\mathrm{Er}^{3+}, \mathrm{Yb}^{3+}$. We find the CRB can be more efficient than MPR and can even make a major contribution to the red UCL. To the best of our knowledge, this is the first time that the CRB has been found to be important to the red emission both in the PL and UCL of the $\mathrm{Er}^{3+}$ $\mathrm{Yb}^{3+}$ system.

\section{MATERIALS AND METHODS}

Sample preparation

The cubic $\mathrm{Y}_{2} \mathrm{O}_{3}: 0.002 \mathrm{Er}^{3+}, x \mathrm{Yb}^{3+}(x=0,0.04,0.1,0.2,0.3)$ samples were prepared by the normal firing precursor method. ${ }^{2}$ The firing precursor is more favorable to achieve uniform and highly crystallized samples than the traditional solid-state reaction. The starting aqueous solutions, $\mathrm{Y}\left(\mathrm{NO}_{3}\right)_{3}, \mathrm{Yb}\left(\mathrm{NO}_{3}\right)_{3}$, and $\mathrm{Er}\left(\mathrm{NO}_{3}\right)_{3}$, with corresponding mole ratios were mixed and stirred vigorously to form a homogeneous solution. The samples were obtained after being dried at $100{ }^{\circ} \mathrm{C}$ for $6 \mathrm{~h}$ and then calcined at $1600{ }^{\circ} \mathrm{C}$ for $6 \mathrm{~h}$. The expression of $\mathrm{Y}_{2} \mathrm{O}_{3}: 0.002 \mathrm{Er}^{3+}, x \mathrm{Yb}^{3+}$ in the present paper means the formula $\mathrm{Y}_{2-0.002-x} \mathrm{Er}_{0.002} \mathrm{Yb}_{x} \mathrm{O}_{3}$. The low $\mathrm{Er}^{3+}$ and high $\mathrm{Yb}^{3+}$ concentrations 
applied in this work were used to achieve a real ETU system and suppress the interaction among $\mathrm{Er}^{3+}$ ions for simplifying the ETU processes.

\section{Spectroscopy measurements}

Steady state PL and UCL spectra were measured using an EI-FS920 fluorimeter with a xenon lamp as an excitation source for PL and a CW $980 \mathrm{~nm}$ laser diode as an excitation source for UCL. The decay curves of PL and UCL were detected using a Triax 550 spectrometer (JobinYvon) and recorded by a Tek-tronix digital oscilloscope (TDS 3052), while a 10 ns pulsed laser with tunable wavelengths from an optical parametric oscillator pumped by a Nd:YAG laser (spectra-physics, GCR 130) was used as an excitation source. In energy level lifetime measurements, the excitation wavelengths were tuned to $520 \mathrm{~nm}$ for $\mathrm{Er}^{3+}{ }^{4} \mathrm{~S}_{3 / 2}, 650 \mathrm{~nm}$ for $\mathrm{Er}^{3+}{ }^{4} \mathrm{~F}_{9 / 2}$ and ${ }^{4} \mathrm{I}_{11 / 2}, 1480 \mathrm{~nm}$ for $\mathrm{Er}^{3+}{ }^{4} \mathrm{I}_{13 / 2}$ and $980 \mathrm{~nm}$ for $\mathrm{Yb}^{3+2} \mathrm{~F}_{5 / 2}$. The lifetime is defined as the area under the decay curve with normalized initial intensity. The UCL spectra under pulse excitation at $980 \mathrm{~nm}$ were detected using a USB4000 spectrometer (Ocean Optics), which gives the time-integrated intensities.

\section{RESULTS AND DISCUSSION}

Observation of the CRB in PL

Figure 1 shows PL spectra of $\mathrm{Y}_{2} \mathrm{O}_{3}: 0.002 \mathrm{Er}^{3+}, x \mathrm{Yb}^{3+}$ under $520 \mathrm{~nm}$ excitation of $\mathrm{Er}^{3+}{ }^{2} \mathrm{H}_{11 / 2}$, which can rapidly relax to the ${ }^{4} \mathrm{~S}_{3 / 2}$ due to their proximity in energy. One can observe that the red $(660 \mathrm{~nm})$ to green $(560 \mathrm{~nm})$ emission intensity ratio $(\mathrm{R} / \mathrm{G})$ increases considerably with increasing $x$. A similar result upon $\mathrm{Er}^{3+}{ }^{4} \mathrm{~F}_{7 / 2}$ excitation with $488 \mathrm{~nm}$ was also observed in $\mathrm{Y}_{2} \mathrm{O}_{3}: \mathrm{Er}^{3+}, \mathrm{Yb}^{3+}$ nanocrystals, ${ }^{11}$ and an interaction between two excited $\mathrm{Er}^{3+}$ ions $\left({ }^{4} \mathrm{~F}_{7 / 2} \rightarrow{ }^{4} \mathrm{~F}_{9 / 2}\right.$ and $\left.{ }^{4} \mathrm{~F}_{9 / 2} \leftarrow{ }^{4} \mathrm{I}_{11 / 2}\right)^{7}$ was considered the main excitation mechanism of the red-emitting ${ }^{4} \mathrm{~F}_{9 / 2}$ state. In the present work, the ${ }^{4} \mathrm{~F}_{7 / 2}$ is not excited and the $\mathrm{Er}^{3+}$ concentration is low, so the above mechanism is not feasible. We found through experimentation that the $\mathrm{R} / \mathrm{G}$ ratio remains unchanged if $\mathrm{La}^{3+}$ or $\mathrm{Lu}^{3+}$ is doped instead of $\mathrm{Yb}^{3+}$, indicating that the ${ }^{4} \mathrm{~S}_{3 / 2}-{ }^{4} \mathrm{~F}_{9 / 2}$ MPR rate hardly changes with rare earth doping. Therefore, we attribute the $\mathrm{Yb}^{3+}$-induced $\mathrm{R} / \mathrm{G}$ increase to the effect of CRB, which benefits from well-matched energy level structures between $\mathrm{Er}^{3+}$ and $\mathrm{Yb}^{3+}$, as sketched in the insert to Figure 1. The

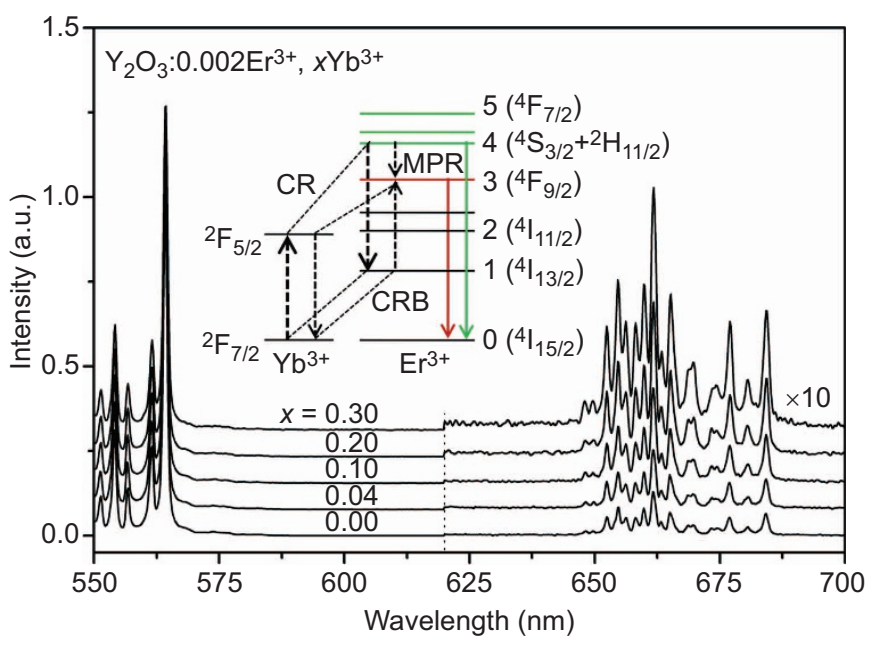

Figure $1 \mathrm{PL}$ spectra upon ${ }^{2} \mathrm{H}_{11 / 2}$ excitation at $520 \mathrm{~nm}$. The green emission intensities are normalized, and the red ones $(620-700 \mathrm{~nm})$ are magnified 10 times. The insert shows the energy level diagram with the $C R$ and $C R B$ processes. $\mathrm{CR}$, cross-relaxation; PL, photoluminescence.
CRB may take place within the same $\mathrm{Er}^{3+}-\mathrm{Yb}^{3+}$ pair, meaning that the $\mathrm{Yb}^{3+}$ ion excited by the CR transfer from $\mathrm{Er}^{3+}$ transfers its energy back again to the same $\mathrm{Er}^{3+}$ ion. The CRB rate in this case is independent of excitation densities, similar to the MPR. If the CRB takes place not within the same $\mathrm{Er}^{3+}-\mathrm{Yb}^{3+}$ pair, i.e., the excitation energy of $\mathrm{Yb}^{3+}$ is not retransferred to the same $\mathrm{Er}^{3+}$ but transferred to any other $\mathrm{Er}^{3+}$ ion in the ${ }^{4} \mathrm{I}_{13 / 2}$ state, then the $\mathrm{CRB}$ rate in this case is dependent on the concentration of the other $\mathrm{Er}^{3+}$ ions and thus dependent on excitation densities. Therefore, the CRB may become important only at high excitation densities. In the present work, the $\mathrm{Yb}^{3+}$-induced $\mathrm{R} / \mathrm{G}$ increase can be observed under weak $520 \mathrm{~nm}$ excitation using a grating monochromator with a xenon lamp. We found that the enlarged $\mathrm{R} / \mathrm{G}$ ratio in the presence of $\mathrm{Yb}^{3+}$ is independent of excitation densities using the xenon lamp as an excitation source. Based on the CRB models mentioned above, we consider that the CRB takes place within the same $\mathrm{Er}^{3+}-\mathrm{Yb}^{3+}$ pair in the samples in this work.

Time evolutions of PL are measured for distinguishing the CRB from the MPR, as shown in Figure 2. With increasing $x$, the appreciable shortening of the ${ }^{4} \mathrm{~S}_{3 / 2}$ lifetime $\left(\tau_{4}\right)$ (Figure $2 \mathrm{a}$ ) is due to the $\mathrm{CR},{ }^{9,10}$ and the small shortening of the ${ }^{4} \mathrm{~F}_{9 / 2}$ lifetime $\left(\tau_{3}\right)$ (Figure $2 \mathrm{~b}$ ) is due to weak coupling ${ }^{12}$ of $\mathrm{Er}^{3+}{ }^{4} \mathrm{~F}_{9 / 2} \rightarrow{ }^{4} \mathrm{I}_{15 / 2}$ with $\mathrm{Yb}^{3+}{ }^{2} \mathrm{~F}_{5 / 2} \leftarrow{ }^{2} \mathrm{~F}_{7 / 2}$. In the time evolution of the red emission after the ${ }^{4} \mathrm{~S}_{3 / 2}$ is populated (Figure 2c), we find that the samples containing $\mathrm{Yb}^{3+}$ appear to undergo a fast build-up process, unlike the $\mathrm{Yb}^{3+}$-free sample that appears as a normal slow rising edge. ${ }^{13}$ Accordingly, the time evolution patterns in the presence of $\mathrm{Yb}^{3+}$ shown in Figure $2 \mathrm{c}$ are the combined patterns of the fast build-up component and the slow build-up component. If one normalizes the initial emission intensity of the fast build-up component (Figure 2c) and denotes the total area under the time evolution curve by $T_{3}$, the proportion of the emitted red photons by the fast build-up component of the total emitted red photons can be calculated by $\tau_{3} / T_{3}$. This proportion is found to be consistent with the proportion of the increment in the $R / G$ ratio (Table 1 ), written as $\alpha=1-\left(\tau_{3} / \tau_{3,0}\right)(\mathrm{R} / \mathrm{G})_{0} /(\mathrm{R} / \mathrm{G})$, where the subscript 0 identifies the case of $x=0$ and $\left(\tau_{3} / \tau_{3,0}\right)(\mathrm{R} / \mathrm{G})_{0}$ is the $\mathrm{R} / \mathrm{G}$ ratio contributed only by MPR in the presence of $\mathrm{Yb}^{3+}$. The result indicates that

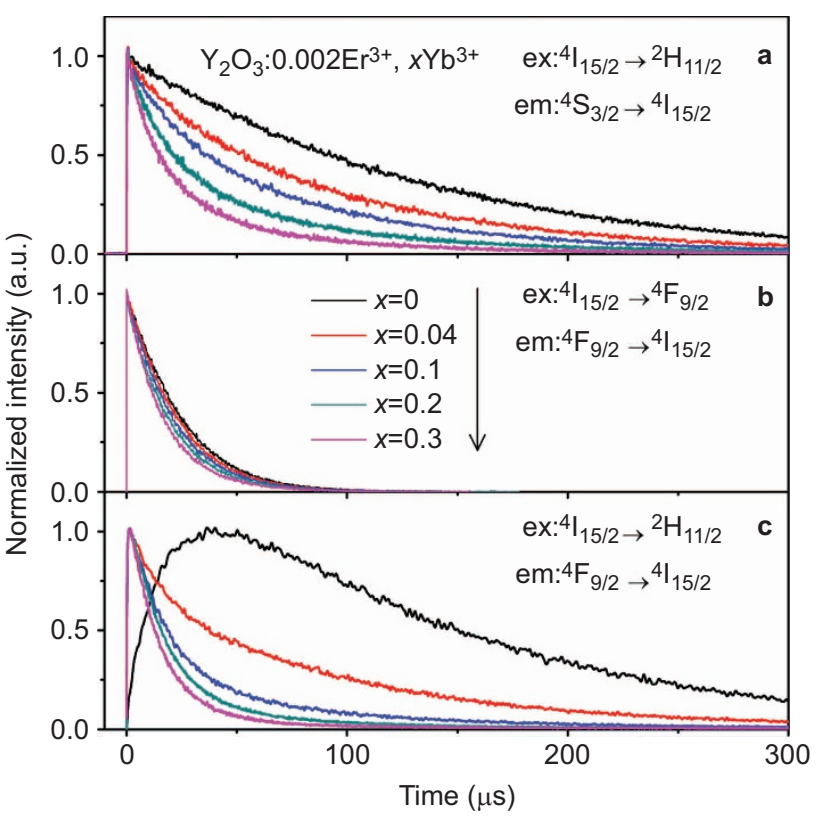

Figure 2 Time evolutions of the green and red emissions. 
Table $1 \mathrm{PL}$ data used to identify the CRB process in $\mathrm{Y}_{2} \mathrm{O}_{3}: 0.002 \mathrm{Er}^{3+}, x \mathrm{Yb}^{3+}$

\begin{tabular}{lllrlll}
\hline$x$ & $\mathrm{R} / \mathrm{G}$ & \multicolumn{1}{c}{$\boldsymbol{I}_{4}$} & $\tau_{4}(\mu \mathrm{s})$ & $\tau_{3}(\mu \mathrm{s})$ & $\tau_{3} / T_{3}$ & \multicolumn{1}{c}{$\alpha$} \\
\hline 0 & 1 & 1 & 124 & 24 & 0 & 0 \\
0.04 & 1.4 & 0.66 & 86 & 22.5 & 0.29 & 0.33 \\
0.10 & 2.15 & 0.33 & 66 & 20.9 & 0.54 & 0.59 \\
0.20 & 3.5 & 0.19 & 43 & 18.9 & 0.73 & 0.78 \\
0.30 & 5.65 & 0.1 & 30 & 17.2 & 0.84 & 0.87 \\
\hline
\end{tabular}

Abbreviation: PL, photoluminescence.

the CRB is a fast process. Accordingly, there must be a fast CR. However, a corresponding fast decay of the green emission is not detected (Figure 2a). We thus deduce that the fast green emission may be completely quenched by the fast CR. This deduction is further evidenced in the following section.

\section{Efficiency of the CRB in PL}

After the ${ }^{4} S_{3 / 2}$ is populated upon $520 \mathrm{~nm}$ excitation, the ${ }^{4} \mathrm{~S}_{3 / 2}$ undergoes depopulation by radiative transition, $\mathrm{MPR}, \mathrm{CRNB}$ and $\mathrm{CRB}$, with respective efficiencies of $\eta_{\mathrm{r} 4}, \eta_{\mathrm{MPR} 43}, \eta_{\mathrm{CRNB}}$ and $\eta_{\mathrm{CRB}}$. Figure 3 shows the comparison of PL spectra under $520 \mathrm{~nm}$ excitation with that under $650 \mathrm{~nm}$ excitation of the ${ }^{4} \mathrm{~F}_{9 / 2}$. Here, the red intensity under $650 \mathrm{~nm}$ excitation is normalized to that under $520 \mathrm{~nm}$ excitation. Under $520 \mathrm{~nm}$ excitation, one can find that the green intensity decreases rapidly with increasing $x$, followed by simultaneous intensity enhancement of $\mathrm{Er}^{3+}{ }^{4} \mathrm{I}_{13 / 2} \rightarrow{ }^{4} \mathrm{I}_{15 / 2}$ emission at $1530 \mathrm{~nm}$ and $\mathrm{Yb}^{3+}{ }^{2} \mathrm{~F}_{5 / 2} \rightarrow{ }^{2} \mathrm{~F}_{7 / 2}$ emission at $1040 \mathrm{~nm}$ compared to that under $650 \mathrm{~nm}$ excitation. The feature is an explicit indication of the CRNB process. In the absence of $\mathrm{Yb}^{3+}$, the $\mathrm{Er}^{3+}{ }^{4} \mathrm{I}_{11 / 2} \rightarrow{ }^{4} \mathrm{I}_{15 / 2}$ emissions for both $520 \mathrm{~nm}$ and $650 \mathrm{~nm}$

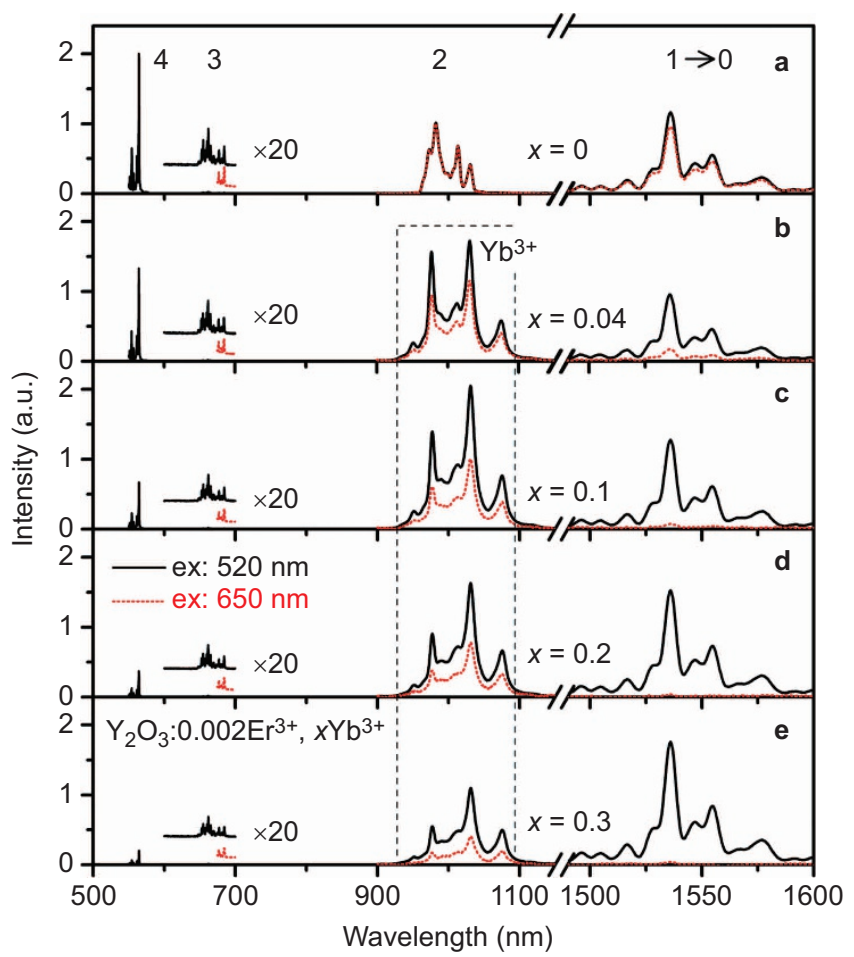

Figure 3 Comparison of $\mathrm{PL}$ spectra upon ${ }^{2} \mathrm{H}_{11 / 2}$ excitation at $520 \mathrm{~nm}$ with that upon ${ }^{4} \mathrm{~F}_{9 / 2}$ excitation at $650 \mathrm{~nm}$. The red emission intensity under $650 \mathrm{~nm}$ excitation is normalized to that under $520 \mathrm{~nm}$ excitation. The red emission intensities (600-700 nm) are magnified 20 times. PL, photoluminescence. excitations can be observed at $1000 \mathrm{~nm}$; they coincide because the population of ${ }^{4} \mathrm{I}_{11 / 2}$ by ${ }^{4} \mathrm{~S}_{3 / 2} \rightarrow{ }^{4} \mathrm{I}_{9 / 2},{ }^{4} \mathrm{I}_{11 / 2}$ radiative transitions for $520 \mathrm{~nm}$ excitation is very small with respect to that from the ${ }^{4} \mathrm{~F}_{9 / 2}$ by cascade MPR. In the presence of $\mathrm{Yb}^{3+}$, the $\mathrm{Er}^{3+}{ }^{4} \mathrm{I}_{11 / 2} \rightarrow{ }^{4} \mathrm{I}_{15 / 2}$ emission is too weak to be identified, and instead, the $\mathrm{Yb}^{3+}$ emission is dominant. This is due to a highly efficient energy transfer from $\mathrm{Er}^{3+}$ ${ }^{4} \mathrm{I}_{11 / 2}$ to $\mathrm{Yb}^{3+}{ }^{2} \mathrm{~F}_{5 / 2}$, ${ }^{14}$ which is also evidenced by the very weak $1530 \mathrm{~nm}$ emission of $\mathrm{Er}^{3+}$ under $650 \mathrm{~nm}$ excitation. In addition, one may find that the $\mathrm{Yb}^{3+}$ emission intensities decrease with increasing $x$ in the $x$ range of $0.1-0.4$ for $520 \mathrm{~nm}$ excitation. The decline is due to concentration quenching because the critical concentration of $\mathrm{Yb}^{3+}$ was observed to be $7.36 \%$ in the $\mathrm{Y}_{2} \mathrm{O}_{3}$ host. ${ }^{15}$

We evaluate $\eta_{\mathrm{r} 4}, \eta_{\mathrm{MPR} 43}, \eta_{\mathrm{CRNB}}$ and $\eta_{\mathrm{CRB}}$ based on the observed increase in the $\mathrm{Er}^{3+} 1530 \mathrm{~nm}$ emission, $\mathrm{Yb}^{3+} 1040 \mathrm{~nm}$ emission and $\mathrm{Er}^{3+} \mathrm{R} / \mathrm{G}$ ratio for $520 \mathrm{~nm}$ excitation. Considering the distinct increment $\left(I_{1}-i_{1}\right)$ in $1530 \mathrm{~nm}$ emission intensity in the presence of $\mathrm{Yb}^{3+}$, one may also observe a small increase for $x=0$. The small increase is attributed to the feeding by the ${ }^{4} \mathrm{~S}_{3 / 2} \rightarrow{ }^{4} \mathrm{I}_{13 / 2}$ radiative transition, which has a big branch ratio $(\beta=0.27) .{ }^{16}$ Hence both the CRNB and the ${ }^{4} \mathrm{~S}_{3 / 2} \rightarrow{ }^{4} \mathrm{I}_{13 / 2}$ radiative transition contribute to the increase. Regarding the experimentally observed $x$-independent ${ }^{4} \mathrm{I}_{13 / 2}$ lifetime, we have, as described in Supplementary Equations (S1)-(S4)

$$
\frac{\eta_{\mathrm{CRNB}}}{\beta \eta_{r_{4}}}=\frac{I_{1}-i_{1}}{I_{4}}\left(\frac{I_{4}}{I_{1}-i_{1}}\right)_{0}-1
$$

where $I_{i}$ and $i_{i}$ are emission intensities from the $i$ th state of $\mathrm{Er}^{3+}$ upon $520 \mathrm{~nm}$ and $650 \mathrm{~nm}$ excitations, respectively. These emission intensities on the right side of Equation (1) are dependent on $x$.

For the increment $\left(I_{\mathrm{d}}-i_{\mathrm{d}}\right)$ in $\mathrm{Yb}^{3+}$ emission intensity, the CRNB is the only contributor, while the rest intensity $\left(i_{\mathrm{d}}\right)$ is populated by quasiresonant energy transfer from $\mathrm{Er}^{3+}{ }^{4} \mathrm{I}_{11 / 2}$ with a transfer efficiency close to 1 due to the high $\mathrm{Yb}^{3+}$ concentration. The ${ }^{4} \mathrm{I}_{11 / 2}$ can be populated from the ${ }^{4} \mathrm{~F}_{9 / 2}$ via the ${ }^{4} \mathrm{I}_{9 / 2}$ by cascade MPR with an efficiency of almost $100 \%$, regarding a very short ${ }^{4} \mathrm{~F}_{9 / 2}$ lifetime (approximately 20 $\mu \mathrm{s})$ compared with its radiative lifetime $(600 \mu \mathrm{s}) .{ }^{16}$ As a result, the population of the ${ }^{4} \mathrm{~F}_{9 / 2}$ by the MPR and the CRB from the ${ }^{4} \mathrm{~S}_{3 / 2}$ finally and completely reaches the ${ }^{4} \mathrm{I}_{11 / 2}$. Hence, the excitation source of the rest $\mathrm{Yb}^{3+}$ emission is the MPR and the CRB from the ${ }^{4} \mathrm{~S}_{3 / 2}$. Then, we have

$$
\frac{\eta_{\mathrm{CRNB}}}{\eta_{\mathrm{MPR}_{43}}+\eta_{\mathrm{CRB}}}=\frac{I_{\mathrm{d}}-i_{\mathrm{d}}}{i_{\mathrm{d}}}
$$

where the subscript $\mathrm{d}$ denotes $\mathrm{Yb}^{3+}$.

The red emission is populated by MPR and CRB from the ${ }^{4} S_{3 / 2}$, so the $R / G$ ratios simply satisfy

$$
\frac{\mathrm{R}}{\mathrm{G}}=\left(\frac{\mathrm{R}}{\mathrm{G}}\right)_{0}\left(1+\frac{\eta_{\mathrm{CRB}}}{\eta_{\mathrm{MPR}_{43}}}\right) \frac{\tau_{3}}{\tau_{3,0}}
$$

Using Equations (1)-(3) with $\eta_{\mathrm{r} 4}+\eta_{\mathrm{MPR} 43}+\eta_{\mathrm{CRNB}}+\eta_{\mathrm{CRB}}=1$, we calculated the efficiencies, as shown in Figure 4a. We obtained $\eta_{\mathrm{MPR} 43} / \eta_{\mathrm{r} 4}=2.08$, which yields $\eta_{\mathrm{r} 4}=32 \%$ for cubic $\mathrm{Y}_{2} \mathrm{O}_{3}: \mathrm{Er}^{3+}$. The measured green PL intensities (square) follow the tracks of $\eta_{\mathrm{r} 4}$ well, but it decreases faster than $\tau_{4}$ with increasing $x$ (Table 1). This feature further implies the existence of an undetected fast decay in the green emission, as indicated in the above section, like the case of the Perrin model. ${ }^{17}$ We may consider an 'active sphere' centered at an $\mathrm{Er}^{3+}$ ion so that its green emission can be completely quenched by a $\mathrm{Yb}^{3+}$ ion located within the sphere through the CR. If the number of the effective cation sites within the sphere is $n$, the fraction $(f)$ of $\mathrm{Er}^{3+}$ ions that 

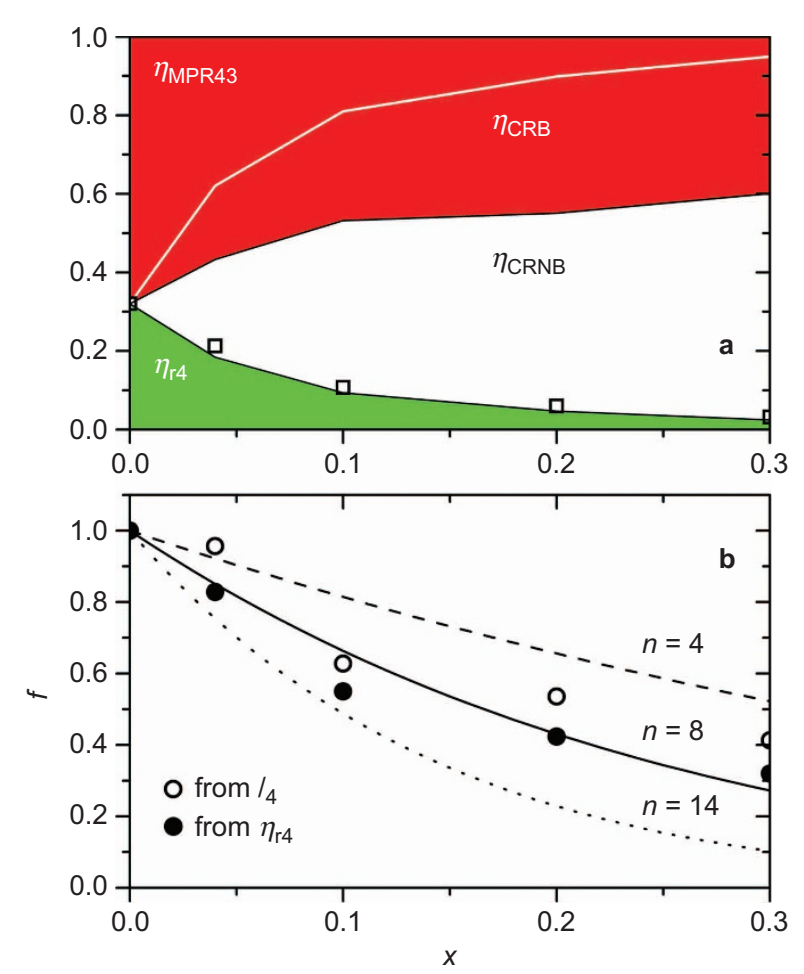

Figure 4 (a) Area graph for efficiencies of various processes for depopulating the ${ }^{4} \mathrm{~S}_{3 / 2}$ state in $\mathrm{Y}_{2} \mathrm{O}_{3}: 0.002 \mathrm{Er}^{3+}, x \mathrm{Yb}^{3+}$ under $520 \mathrm{~nm}$ excitation. The measured green emission intensities are also shown (squares). (b) Comparison of experimental and theoretical dependence of $f$ on $x$. The experimental data are obtained by $\left(I_{4} / /_{4,0}\right)\left(\tau_{4,0} / \tau_{4}\right)$ (circle) or $\left(\eta_{r} / \eta_{r 4,0}\right)\left(\tau_{4,0} / \tau_{4}\right)$ (filled circle).

have no $\mathrm{Yb}^{3+}$ in the sphere satisfies the binomial distribution: $f=(1-x / 2)^{n}$. Considering that the green luminescence yield $\left(I_{4}\right.$ or $\eta_{\mathrm{r} 4}$ ) can be regarded as the area under its decay curve including the undetected fast component, then $f$ can be obtained either by $\left(I_{4} /\right.$ $\left.I_{4,0}\right)\left(\tau_{4,0} / \tau_{4}\right)$ or $\left(\eta_{\mathrm{r} 4} / \eta_{\mathrm{r} 4,0}\right)\left(\tau_{4,0} / \tau_{4}\right)$ from the decay picture of the green emission containing a fast component with a lifetime close to 0 and a slow one with a lifetime of $\tau_{4}$, weighted by $1-f$ and $f$, respectively, as described in Supplementary Fig. S1 and Equation (S5).

In cubic $\mathrm{Y}_{2} \mathrm{O}_{3}$, there are two $\mathrm{Y}$ sites with respective $C_{3 i}$ and $C_{2}$ symmetries. The $C_{3 i}$ has an inversion center on this site; the $4 f-4 f$ transition of a rare earth ion is forbidden. Therefore, only the $C_{2}$ site is effective. A $C_{2}$ site has four of the first nearest $C_{2}$ sites, four of the second nearest $C_{2}$ sites and six of the next nearest $C_{2}$ sites. The fitting results point to $n=8$, as shown in Figure $4 \mathrm{~b}$, indicating that the green emission of an $\mathrm{Er}^{3+}$ can be completely quenched only by an $\mathrm{Yb}^{3+}$ located in the nearest site of the $\mathrm{Er}^{3+}$ ion. As a result, the nearest $\mathrm{Er}^{3+}-\mathrm{Yb}^{3+}$ pairs exhibit completely quenched green emission and produce the undetected fast decay of the green emission. As we have observed, the CRB is a fast process; thus, the CRB takes place only within the nearest $\mathrm{Er}^{3+}-\mathrm{Yb}^{3+}$ pairs. Of course, the occurrence of a fast CRNB is also expected in the nearest $\mathrm{Er}^{3+}-\mathrm{Yb}^{3+}$ pairs. Accordingly, the distant $\mathrm{Er}^{3+}-\mathrm{Yb}^{3+}$ pairs can only perform the slow CRNB to reduce $\tau_{4}$. In Figure $4 \mathrm{a}$, over $30 \%$ of the CR is the CRB upon $520 \mathrm{~nm}$ excitation, and the CRB becomes more important than the MPR for populating the red-emitting state from the green state as $x \geqslant 0.1$. The efficient CRB benefits from the nearest $\mathrm{Er}^{3+}-\mathrm{Yb}^{3+}$ pairs that can compete with the energy transfer from the $\mathrm{Yb}^{3+}$ ions excited by the $\mathrm{CR}$ to other $\mathrm{Yb}^{3+}$ ions outside the pairs. The nearest $\mathrm{Er}^{3+}-\mathrm{Yb}^{3+}$ pair ensures that the CRB takes place within the pair because the energy back transfer from $\mathrm{Yb}^{3+}$ to other $\mathrm{Er}^{3+}$ undergoes a longer interaction distance due to the low $\mathrm{Er}^{3+}$ concentration used in this work. Hence, no dependency of the CRB on excitation densities is observed in the present work. The Perrin model, like CRB, may be governed by the exchange mechanism described by Inokuti and Hirayama. ${ }^{17}$

In $\mathrm{CRB}$, the $\mathrm{CR}$ transfer from $\mathrm{Er}^{3+}\left({ }^{4} \mathrm{~S}_{3 / 2} \rightarrow{ }^{4} \mathrm{I}_{13 / 2}\right)$ to $\mathrm{Yb}^{3+}$ $\left({ }^{2} \mathrm{~F}_{5 / 2} \leftarrow{ }^{2} \mathrm{~F}_{7 / 2}\right)$ and the back transfer from $\mathrm{Yb}^{3+}\left({ }^{2} \mathrm{~F}_{5 / 2} \rightarrow{ }^{2} \mathrm{~F}_{7 / 2}\right)$ to $\mathrm{Er}^{3+}\left({ }^{4} \mathrm{~F}_{9 / 2} \leftarrow{ }^{4} \mathrm{I}_{13 / 2}\right)$ suffer from an energy mismatch of $\sim 1700 \mathrm{~cm}^{-1}$ and $\sim 1500 \mathrm{~cm}^{-1}$, respectively, which is more than twice as large as the cutoff phonon energy of $600 \mathrm{~cm}^{-1}$ in $\mathrm{Y}_{2} \mathrm{O}_{3}$. The performance of the energy transfers thus requires emission of two or three phonons to make up for the large energy mismatch. In spite of requirement of several phonons, the high $\mathrm{Yb}^{3+}$ concentration and the nearest $\mathrm{Er}^{3+}-$ $\mathrm{Yb}^{3+}$ pairs make the transfers efficient.

\section{Effect of the CRB on UCL}

Figure 5 shows the UCL spectra for $\mathrm{Y}_{2} \mathrm{O}_{3}: 0.002 \mathrm{Er}^{3+}, 0.1 \mathrm{Yb}^{3+}$ upon pulse and CW infrared $(980 \mathrm{~nm})$ excitations. For comparison, its PL spectrum is also presented. The phenomenon ${ }^{11,18-20}$ that the $\mathrm{R} / \mathrm{G}$ ratio in PL is much less than that in UCL is evident. Ignoring the CRB, it was naturally deduced from the phenomenon that the ETU from ${ }^{4} \mathrm{I}_{13 / 2}$ makes the major contribution to the red UCL. ${ }^{18,19}$ If the CRB is operative, the above deduction could be possibly invalid because of the following reasons: the nearest $\mathrm{Er}^{3+}-\mathrm{Yb}^{3+}$ pairs can be preferentially excited to the $\mathrm{Er}^{3+}{ }^{4} \mathrm{~S}_{3 / 2}$ state by two sequential energy transfers from $\mathrm{Yb}^{3+}$ in ETU, as shown in the insert to Figure 5. Meanwhile, the CRB enables the nearest $\mathrm{Er}^{3+}-\mathrm{Yb}^{3+}$ pairs to only have a red emission in the visible spectral region. In the PL measurement, however, each $\mathrm{Er}^{3+}$ ion has the same probability to be excited to the ${ }^{4} S_{3 / 2}$ state by ground state absorption. Based on the analysis above, a much smaller $\mathrm{R} / \mathrm{G}$ ratio of PL than that of UCL is still achievable if the CRB makes the major contribution to the red UCL. In other words, the observation of a much smaller R/G ratio for PL than for UCL cannot exclude the major role of the ${ }^{4} \mathrm{~S}_{3 / 2}$ state in populating the red-emitting state in the upconversion of the $\mathrm{Er}^{3+}-\mathrm{Yb}^{3+}$ system. In our experiment, the PL and UCL temporal behaviors of $\mathrm{Y}_{2} \mathrm{O}_{3}: 0.002 \mathrm{Er}^{3+}, 0.1 \mathrm{Yb}^{3+}$ (Figure 6)

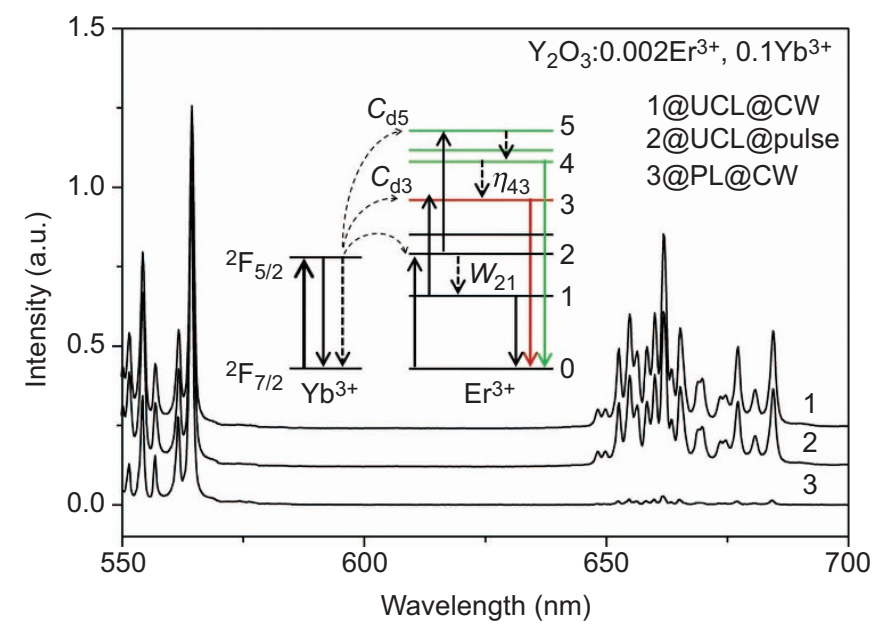

Figure 5 UCL spectra upon CW and upon pulse $980 \mathrm{~nm}$ excitations as well as a $\mathrm{PL}$ spectrum for $\mathrm{Y}_{2} \mathrm{O}_{3}: 0.002 \mathrm{Er}^{3+}, 0.1 \mathrm{Yb}^{3+}$. The green emission intensities are normalized. The CW excitation density is as low as $50 \mathrm{~mW} \mathrm{~cm}^{-2}$. The insert is the diagram of ETU processes for the $\mathrm{Er}^{3+}-\mathrm{Yb}^{3+}$ system. ETU, energy transfer upconversion; PL, photoluminescence; UCL, upconversion luminescence. 


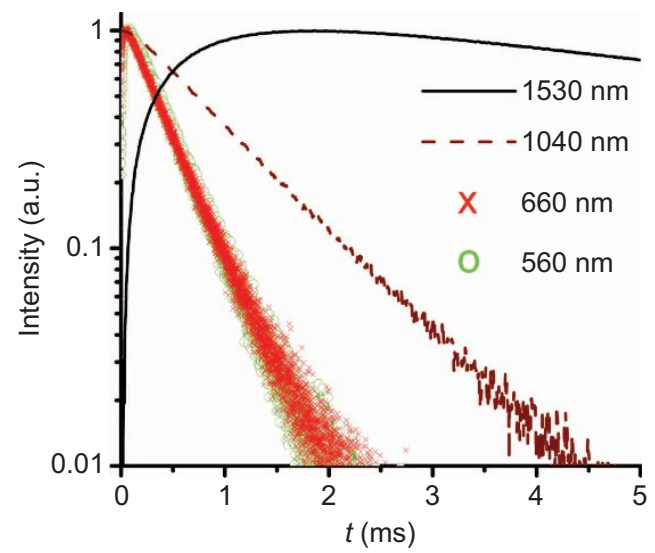

Figure 6 Time evolutions of the green UCL $(560 \mathrm{~nm})$, the red UCL $(670 \mathrm{~nm})$, $\mathrm{Yb}^{3+}$ emission $(1040 \mathrm{~nm})$ and $\mathrm{Er}^{3+}$ emission $(1530 \mathrm{~nm})$ from ${ }^{4} \mathrm{I}_{13 / 2}$ after pulse $980 \mathrm{~nm}$ excitation for $\mathrm{Y}_{2} \mathrm{O}_{3}: 0.002 \mathrm{Er}^{3+}, 0.1 \mathrm{Yb}^{3+}$. UCL, upconversion luminescence.

demonstrate that the ${ }^{4} \mathrm{~F}_{9 / 2}$ is populated mainly from ${ }^{4} \mathrm{~S}_{3 / 2}$ in ETU, as analyzed below.

From Figure 6, the $\mathrm{Yb}^{3+}$ emission decays exponentially (with a decay time of $\tau_{\mathrm{d}}=840 \mu \mathrm{s}$ ), indicating the rapid diffusion limited energy transfer. The decay time of the green UCL is $391 \mu \mathrm{s}$, and that of the red is $412 \mu \mathrm{s}$. These UCL decay times are much longer than $\tau_{4}$ ( $66 \mu \mathrm{s})$ and $\tau_{3}(20.9 \mu \mathrm{s})$ (Table 1), exhibiting the typical effect of ETU. Thus, the UCL decay function is mainly determined by the product of the decay functions of the $\mathrm{Yb}^{3+2} \mathrm{~F}_{5 / 2}$ and $\mathrm{Er}^{3+}$ intermediate states. The green UCL decay time approaches $\tau_{\mathrm{d}} / 2$, reflecting that $\mathrm{Er}^{3+}{ }^{4} \mathrm{I}_{11 / 2}$, as the intermediate state for the green upconversion, has the same decay time as $\mathrm{Yb}^{3+2} \mathrm{~F}_{5 / 2}$ because the two levels are thermally coupled in case of rapid energy transfer between them, as predicated earlier. ${ }^{14}$ The approximation of the red UCL decay time to the green one indicates that the ${ }^{4} \mathrm{~F}_{9 / 2}$ is populated mainly from the ${ }^{4} S_{3 / 2}$ under pulse infrared excitation; otherwise, the red could have a decay time close to $\tau_{\mathrm{d}}(840$ $\mu \mathrm{s})$ because of the quite long lifetime ( $\left.\tau_{1}=8.4 \mathrm{~ms}\right)$ of the intermediate ${ }^{4} \mathrm{I}_{13 / 2}$ state. Now, we want to determine if the ${ }^{4} \mathrm{~F}_{9 / 2}$ is still populated mainly from the ${ }^{4} S_{3 / 2}$ under $\mathrm{CW}$ infrared excitation.

In Figure 5, one may find that the R/G ratio in UCL for CW excitation, (R/G) $)_{\mathrm{UCL}} @ \mathrm{CW}$, is larger than that for pulse excitation, (R/ G) UCL @pulse. The smaller (R/G) UCC @pulse arises from the low build-up process of the ${ }^{4} \mathrm{I}_{13 / 2}$ state (Figure 6), as described in Supplementary Equation (S10), which slows down the ETU from the ${ }^{4} \mathrm{I}_{13 / 2}$ to the ${ }^{4} \mathrm{~F}_{9 / 2}$ after pulse infrared excitation. Taking the different $\mathrm{R} / \mathrm{G}$ ratios into account, the percentages of the red component $R_{4}$, populated from the ${ }^{4} \mathrm{~S}_{3 / 2}$, and $R_{1}$, from the ${ }^{4} \mathrm{I}_{13 / 2}$, can be evaluated.

If the ${ }^{4} S_{3 / 2}$ and the ${ }^{4} \mathrm{~F}_{9 / 2}$ states are populated under infrared excitation in ETU, we denote the mean emitting efficiencies of the two states by $\eta_{\mathrm{G}}$ and $\eta_{\mathrm{R}}$, respectively. While the mean depopulating efficiency from the ${ }^{4} \mathrm{~S}_{3 / 2}$ to the ${ }^{4} \mathrm{~F}_{9 / 2}$ via MPR and the CRB is denoted by $\eta_{43}$, the $\mathrm{R} / \mathrm{G}$ ratio in $\mathrm{UCL}$ is

$$
\left(\frac{\mathrm{R}}{\mathrm{G}}\right)_{\mathrm{UCL}}=\frac{\left(1+R_{1} / R_{4}\right) \eta_{43} \eta_{\mathrm{R}}}{\eta_{\mathrm{G}}}
$$

where $\eta_{\mathrm{G}}, \eta_{\mathrm{R}}$ and $\eta_{43}$ are unchanged for $\mathrm{CW}$ or pulse infrared excitations. In view of the high $\mathrm{Yb}^{3+}$ and low $\mathrm{Er}^{3+}$ concentrations, we assume here the simplest possible model; (i) ETU undergoes the rapid diffusion limited energy transfer from $\mathrm{Yb}^{3+}$ that can be described by an average energy transfer rate; (ii) the ground and excited states absorption of $\mathrm{Er}^{3+}$ is neglected. We also assume the ${ }^{4} \mathrm{~F}_{7 / 2}$ can rapidly and completely relax down to the ${ }^{4} S_{3 / 2}$ state due to their proximity in energy.

From the diagram of ETU processes inserted in Figure 5, the population flow from the ${ }^{4} \mathrm{I}_{11 / 2}$ to the ${ }^{4} \mathrm{~F}_{7 / 2}$ is $C_{\mathrm{d} 5} n_{\mathrm{d}} n_{2}$ and that from the ${ }^{4} \mathrm{I}_{13 / 2}$ to the ${ }^{4} \mathrm{~F}_{9 / 2}$ is $C_{\mathrm{d} 3} n_{\mathrm{d}} n_{1}$. Under CW excitation, the population flow is time independent, and thus, $R_{4} @ \mathrm{CW}=\eta_{\mathrm{R}} \eta_{43} C_{\mathrm{d} 5} n_{\mathrm{d}} n_{2}$ and $R_{1} @ \mathrm{CW}=\eta_{\mathrm{R}} C_{\mathrm{d} 3} n_{\mathrm{d}} n_{1}$, where $C_{\mathrm{d} i}$ is the coefficient for energy transfer from donor $\mathrm{Yb}^{3+}$ to the $i$ th state of $\mathrm{Er}^{3+}$, and $n_{\mathrm{d}}$ and $n_{i}$ are populations of $\mathrm{Yb}^{3+}{ }^{2} \mathrm{~F}_{5 / 2}$ and $\mathrm{Er}^{3+}$ in the $i$ th state, respectively. Then, the $R_{1} / R_{4}$ ratio for $\mathrm{CW}$ infrared excitation is expressed as

$$
\left(R_{1} / R_{4}\right) @ \mathrm{CW}=\left(C_{\mathrm{d} 3} / C_{\mathrm{d} 5}\right) W_{21} \tau_{1} / \eta_{43}
$$

where $W_{21}$ is the sum of the ${ }^{4} \mathrm{I}_{11 / 2}-{ }^{4} \mathrm{I}_{13 / 2}$ radiative and MPR rates, which satisfies $W_{21} n_{2}=n_{1} / \tau_{1}$ for a steady state excitation.

Under pulse infrared excitation of $\mathrm{Yb}^{3+}$, we detect the upconversion luminescence yield over time. Based on the rate equations for describing ETU in the $\mathrm{Er}^{3+}-\mathrm{Yb}^{3+}$ system, as in Supplementary Equations (S7)-(S13), we obtain

$$
\left(R_{1} / R_{4}\right) @ \text { pulse }=\left[\tau_{\mathrm{d}} /\left(\tau_{1}+\tau_{\mathrm{d}}\right)\right]\left(C_{\mathrm{d} 3} / C_{\mathrm{d} 5}\right) W_{21} \tau_{1} / \eta_{43}
$$

From Figure 5, the R/G ratio in UCL for CW excitation is 1.2 times as large as that for pulse excitation,

$$
(\mathrm{R} / \mathrm{G})_{\mathrm{UCL}} @ \mathrm{CW}=1.2(\mathrm{R} / \mathrm{G})_{\mathrm{UCL}} @ \text { pulse }
$$

Combining Equations (4) $-(7)$ with $\tau_{\mathrm{d}}=840 \mu$ s and $\tau_{1}=8.4 \mathrm{~ms}$ gives $\left(R_{1} / R_{4}\right) @$ pulse $=0.02$ and $\left(R_{1} / R_{4}\right) @ \mathrm{CW}=0.22$ for $\mathrm{Y}_{2} \mathrm{O}_{3}: 0.002 \mathrm{Er}^{3+}$, $0.1 \mathrm{Yb}^{3+}$. These values mean that only $2 \%$ of the red UCL is populated from the ${ }^{4} \mathrm{I}_{13 / 2}$ and $98 \%$ from the ${ }^{4} \mathrm{~S}_{3 / 2}$ under pulse infrared excitation, and for CW infrared excitation, $18 \%$ of the red UCL is populated from the ${ }^{4} \mathrm{I}_{13 / 2}$ and $82 \%$ from the ${ }^{4} \mathrm{~S}_{3 / 2}$. The main role of the ${ }^{4} \mathrm{~S}_{3 / 2}$ in populating the red UCL reflects a strong CRB. Meanwhile, the small contribution of the ETU from the ${ }^{4} \mathrm{I}_{13 / 2}$ is partially due to a small value of $C_{\mathrm{d} 3} / C_{\mathrm{d} 5}$ that is calculated to be $0.124 \eta_{43}$ using Equation (5). In this calculation, a $W_{21}$ of $218 \mathrm{~s}^{-1}$ is used, which is determined from our measured ${ }^{4} \mathrm{I}_{11 / 2}$ lifetime $\left(\tau_{2,0}\right)$ of $2.73 \mathrm{~ms}$ in $\mathrm{Y}_{2} \mathrm{O}_{3}: 0.002 \mathrm{Er}^{3+}$ and the reported ${ }^{16}$ intrinsic ${ }^{4} \mathrm{I}_{11 / 2}$ lifetime of $6.03 \mathrm{~ms}$ and ${ }^{4} \mathrm{I}_{11 / 2} \rightarrow{ }^{4} \mathrm{I}_{13 / 2}$ radiative branch ratio of 0.108 . The small $C_{\mathrm{d} 3} / C_{\mathrm{d} 5}$ ratio is well understood in view of a large energy mismatch $\left(\sim 1500 \mathrm{~cm}^{-1}\right)$ in the transfer from $\mathrm{Yb}^{3+}\left({ }^{2} \mathrm{~F}_{5 / 2} \rightarrow{ }^{2} \mathrm{~F}_{7 / 2}\right)$ to $\mathrm{Er}^{3+}\left({ }^{4} \mathrm{~F}_{9 / 2} \leftarrow{ }^{4} \mathrm{I}_{13 / 2}\right)$ relating to $C_{\mathrm{d} 3}$, while the energy transfer from $\mathrm{Yb}^{3+}\left({ }^{2} \mathrm{~F}_{5 / 2} \rightarrow{ }^{2} \mathrm{~F}_{7 / 2}\right)$ to $\mathrm{Er}^{3+}\left({ }^{4} \mathrm{~F}_{7 / 2} \leftarrow{ }^{4} \mathrm{I}_{11 / 2}\right)$ relating to $C_{\mathrm{d} 5}$ is quasi-resonant.

Obviously, a high $\mathrm{Yb}^{3+}$ concentration and preferential excitation of the nearest $\mathrm{Er}^{3+}-\mathrm{Yb}^{3+}$ pairs in ETU can promote the CRB process. Meanwhile, increasing the population ratio of $\mathrm{Er}^{3+}{ }^{4} \mathrm{I}_{11 / 2}$ to ${ }^{4} \mathrm{I}_{13 / 2}$ is beneficial to ETU from the ${ }^{4} \mathrm{I}_{11 / 2}$ to the ${ }^{4} \mathrm{~F}_{7 / 2}$, and it thus can promote the contribution of the CRB to the red UCL against the ETU from the ${ }^{4} \mathrm{I}_{13 / 2}$ to the ${ }^{4} \mathrm{~F}_{9 / 2}$. Therefore, the host material with low cutoff phonon energy likely has a pronounced CRB process like $\mathrm{Y}_{2} \mathrm{O}_{3}$. However, this population ratio is usually reduced in nanomaterials because the ${ }^{4} \mathrm{I}_{11 / 2}-{ }^{4} \mathrm{I}_{13 / 2}$ MPR is strongly enhanced by coupling with $\mathrm{OH}^{-}$groups on the large surface of the nanomaterials. ${ }^{21}$

\section{CONCLUSIONS}

We observed a pronounced CRB process for populating the $\mathrm{Er}^{3+}$ redemitting state from its green state in cubic $\mathrm{Y}_{2} \mathrm{O}_{3}: \mathrm{Er}^{3+}, \mathrm{Yb}^{3+}$. We found the CRB can be more efficient than MPR and can even make the major contribution to the red emission in both PL and UCL. The CRB takes place only in the nearest $\mathrm{Er}^{3+}-\mathrm{Yb}^{3+}$ pairs, and thus, it is a fast and 
efficient process at low excitation densities. The present research methods may be applied to a general $\mathrm{Er}^{3+}-\mathrm{Yb}^{3+}$ system, and the identification of the importance of the CRB in other material hosts is expected.

\section{ACKNOWLEDGEMENTS}

This work has been supported by NSFC (Grants No. 10834006, 51172226, 61275055 and 11274007).

1 Auzel F. Upconversion and anti-stokes processes with $\mathrm{f}$ and $\mathrm{d}$ ions in solids. Chem Rev 2004; 104: 139-174.

2 Li J, Zhang J, Hao Z, Zhang X, Zhao J et al. Intense upconversion luminescence and origin study in $\mathrm{Tm}^{3+} / \mathrm{Yb}^{3+}$ codoped calcium scandate. Appl Phys Lett 2012; 101: 121905.

3 Qin W, Liu Z, Sin C, Wu C, Qin G et al. Multi-ion cooperative processes in Yb ${ }^{3+}$ clusters. Light Sci Appl 2014; 3: e193, doi:10.1038/Isa.2014.74.

4 Mobert PEA, Heumann E, Huber G, Chai BHT. Green $\mathrm{Er}^{3+}: \mathrm{YLiF}_{4}$ upconversion laser at $551 \mathrm{~nm}$ with $\mathrm{Yb}^{3+}$ codoping: a novel pumping scheme. Opt Lett 1997; 22: 14121414.

5 Zijlmans H, Bonnet J, Burton J, Kardos K, Vail T et al. Detection of cell and tissue surface antigens using up-converting phosphors: a new reporter technology. Anal Biochem 1999; 267: 30-36.

6 Uitert LG, Levinstein HJ, Grodkiewicz WH. Infrared stimulable rare earth oxy-halide phosphors: their synthesis, properties and applications. Mater Res Bull 1969; 4: 381-389.

7 Wittke JP, Ladany I, Yocom PN. $\mathrm{Y}_{2} \mathrm{O}_{3}: \mathrm{Yb}$ :Er-new red-emitting infrared-excited phosphor. J Appl Phys 1972; 43: 595-600.

8 Sommerdijk JL, Bril A. Visible luminescence of $\mathrm{Er}^{3+}, \mathrm{Yb}^{3+}$ under IR excitation. In: Williams F, editor. Luminescence of Crystals, Molecules and Solutions. New York: Plenum Press; 1973, p86-91.

9 Ostermayer FW. Preparation and properties of infrared-to-visible conversion phosphors. Metall Trans 1971; 2: 747-755.
10 Solis D, Rosa E, Meza O, Diaz-Torres LA, Salas $\mathrm{P}$ et al. Role of $\mathrm{Yb}^{3+}$ and $\mathrm{Er}^{3+}$ concentration on the tunability of green-yellow-red upconversion emission of codoped $\mathrm{ZrO}_{2}: \mathrm{Yb}^{3+}-\mathrm{Er}^{3+}$ nanocrystals. J Appl Phys 2010; 108: 023103.

11 Vetrone F, Boyer JC, Capobianco JA, Speghini A, Bettinelli M. Significance of $\mathrm{Yb}^{3+}$ concentration on the upconversion mechanisms in codoped $\mathrm{Y}_{2} \mathrm{O}_{3}: \mathrm{Er}^{3+}, \mathrm{Yb}^{3+}$ nanocrystals. J Appl Phys 2004; 96: 661-667.

12 Kuroda H, Shionoya S, Kushida T. Mechanism and controlling factors of infrared to visible conversion process in $\mathrm{Er}^{3+}$ and $\mathrm{Yb}^{3+}$ doped phosphors. J Phys Soc Jpn 1972 33: $125-141$.

13 Weber MJ. Selective excitation and decay of $\mathrm{Er}^{3+}$ fluorescence in $\mathrm{LaF}_{3}$. Phys Rev 1967; 156: 231-241.

14 Ziel JP, Uitert LG, Grodkiewicz WH. Factors controlling infrared pumped visible emission of $\mathrm{Yb}^{3+}-\mathrm{Er}^{3+}$ in the scheelites. J Appl Phys 1970; 41: 3308-3315.

15 Auzel F, Baldacchini G, Laversenne L, Boulon G. Radiation trapping and selfquenching analysis in $\mathrm{Yb}^{3+}, \mathrm{Er}^{3+}$, and $\mathrm{Ho}^{3+}$ doped $\mathrm{Y}_{2} \mathrm{O}_{3}$. Opt Mater 2003; 24: 103-109.

16 Sardar DK, Nash KL, Yow RM, Gruber JB. Absorption intensities and emission cross section of intermanifold transition of $\mathrm{Er}^{3+}$ in $\mathrm{Er}^{3+}: \mathrm{Y}_{2} \mathrm{O}_{3}$ nanocrystals. J Appl Phys 2007; 101: 113115.

17 Inokuti M, Hirayama F. Influence of energy transfer by the exchange mechanism on donor luminescence. J Chem Phys 1965; 43: 1978-1989.

18 Sommerdijk JL, Wanmaker WL, Verriet JG. Infrared excited visible luminescence in oxidic lattices doped with $\mathrm{Yb}^{3+}$ and $\mathrm{Er}^{3+}$. J Lumin 1971; 4: 404-416.

19 Sommerdijk JL. On the excitation mechanism of the infrared excited visible luminescence in $\mathrm{Yb}^{3+}, \mathrm{Er}^{3+}$ doped fluorides. J Lumin 1971; 4: 441-449.

20 Singh V, Rai VK, Haase $\mathrm{M}$. Intense green and red upconversion emission of $\mathrm{Er}^{3+}, \mathrm{Yb}^{3+}$ co-doped $\mathrm{CaZrO}_{3}$ obtained by a solution combustion reaction. J App/ Phys 2012; 112 063105.

21 Eilers $\mathrm{H}$. Effect of particle/grain size on the optical properties of $\mathrm{Y}_{2} \mathrm{O}_{3}: \mathrm{Er}$, Yb. J Alloys Compd 2009; 474: 569-572.

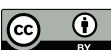

This work is licensed under a Creative Commons Attribution 3.0 Unported License. The images or other third party material in this article are included in the article's Creative Commons license, unless indicated otherwise in the credit line; if the material is not included under the Creative Commons license, users will need to obtain permission from the license holder to reproduce the material. To view a copy of this license, visit http://creativecommons.org/licenses/by/3.0/ 